\title{
CULTURA DE CONSUMO E SIGNIFICADOS DAS MARCAS
}

A relação entre cultura e consumo é objeto de investigação das Ciências Sociais, especialmente da Antropologia, que tradicionalmente estuda a cultura e as relações interculturais, e desde a década de 1980 volta-se para investigar como as pessoas se relacionam com os objetos materiais. Os estudos do consumo na perspectiva cultural partem da noção de cultura enquanto sistema simbólico. Assim, tem contribuído para o avanço do conhecimento sobre 0 consumo simbólico o modo como os consumidores transformam os significados codificados nas propagandas e nas marcas de produtos para construir suas identidades e estilos de vida, comunicar valores e sentimentos, compartilhar emoções e experiências e marcar posições sociais. A professora Tania Limeira, da FGV-EAESP, que vem realizando pesquisas neste campo, oferece indicações que podem auxiliar no entendimento do tema.
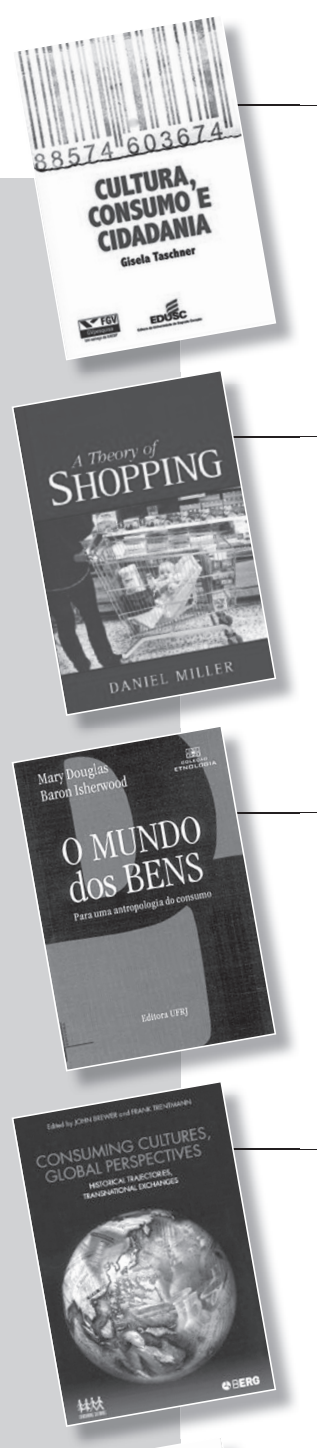

CULTURA, CONSUMO E CIDADANIA. Gisela Taschner. São Paulo: EDUSC, 2009. 200 p.

0 livro aborda a relação entre cultura, consumo e cidadania, analisando os momentos-chave da formação da cultura do consumo e dos movimentos de defesa do consumidor. A cidadania, enquanto reconhecimento de um indivíduo como membro de uma coletividade, tornou-se mediada pelo mercado, e 0 acesso aos bens de consumo é considerado um direito de cidadania. É também analisada a evolução do turismo como forma peculiar de expansão do consumo contemporâneo.

A THEORY OF SHOPPING. Daniel Miller. Ithaca: Cornell University Press, 1998. 180p.

Este livro é uma referência seminal para a compreensão da cultura de consumo. 0 autor é um dos pioneiros na reflexão antropológica acerca do mundo material, ao investigar os objetos materiais que viabilizam e participam das práticas contemporâneas de consumo. 0 autor analisa 0 ato de comprar como uma expressão de amor, um rito devocional que fortalece os laços de parentesco, opondo-se à noção de consumo associado a materialismo e a hedonismo.

O MUNDO DOS BENS: para uma Antropologia do Consumo. Mary Douglas e Baron Isherwood. Rio Janeiro: Editora UFRJ, 2004.

Esta é uma obra de referência no campo dos estudos da cultura de consumo, pois traz um novo olhar sobre os motivos que levam as pessoas a buscar prazer e felicidade com as experiências de consumo. Sendo algo básico na cultura contemporânea, para os autores, a função essencial do consumo é criar significados culturais e comunicar valores socialmente compartilhados que constroem identidades, sustentam estilos de vida, regulam relações sociais e expressam princípios.

CONSUMING CULTURES, GLOBAL PERSPECTIVES: historical trajectories, transnational exchanges. John Brewer e Frank Trentmann. Londres: Berg Publishers, 2006. 352 p.

Nesta obra são discutidas as relações entre modernidade e consumo, numa perspectiva global. Com base nos estudos com consumidores de diversos países, os autores analisam a genealogia do consumidor moderno, bem como as políticas contemporâneas em relação ao consumo. Os autores problematizam as noções de globalização e consumerismo, concluindo que a globalização não provocou a homogeneização das culturas de consumo, mas, ao contrário, há significativa diversidade cultural nos diversos países pesquisados.

NETNOGRAPHY: doing ethnographic research online. Robert Kozinets, Toronto: SAGE Publications, 2010. $232 p$.

Este livro aborda a netnografia, uma forma de pesquisa etnográfica que investiga aspectos culturais das redes sociais e comunidades on-line. Discute a metodologia deste tipo de pesquisa com foco nas questões éticas. São dadas informações detalhadas para que os pesquisadores possam se utilizar deste método para compreender em profundidade os processos comunicacionais e de sociabilidade na internet, ou seja, como os indivíduos se comunicam e interagem no ambiente virtual. 